\title{
Determinação da Concentração de Fosfato em Amostras de Detergentes em Pó Utilizando Detecção Titulométrica
}

\author{
Ana Carla da S. Souza \\ Universidade Severino Sombra, CECETEN, Curso de Química \\ Industrial, anasilva27@hotmail.com \\ Carlos Eduardo Cardoso \\ Universidade Severino Sombra, CECETEN, Curso de Química \\ Industrial, cardoso@uss.br \\ Miguel Rascado Fraguas Neto \\ Universidade Severino Sombra, CECETEN, Curso de Química \\ Industrial, fraguas@uss.br
}

\begin{abstract}
Resumo: O uso excessivo de fósforo na forma de tripolifosfato de sódio (STPP) em detergentes em pó tem e contribuido de maneira significativa no processo de eutrofização da águas e consequentemente na poluição dos corpos hídricos. Visando a redução e eventual eliminação do uso de fosfato nos detergentes, o Conselho Nacional do Meio Ambiente criou a resolução CONAMA 359/05, que dispõe sobre a regulamentação do teor de fósforo em detergentes em pó para o uso no mercado nacional. O presente trabalho tem como objetivo determinar e comparar a concentração de fosfato em detergentes em pó, fabricados em três países (Omã, França e Brasil), de acordo com esta resolução. Para determinar a concentração do fosfato utilizou-se a técnica de titulação por volumetria.
\end{abstract}

Palavras- chave: Fosfato. Detergente em pó. Eutrofização.

\section{Determination Of The Concentration Of Phosphate In Samples Of Powder Detergents Using Detection Titrimetric}

\begin{abstract}
The extreme use of phosphorus in the form of sodium tripolyphosphate (STPP) in powder detergents has contributed in significant way in the process of eutrophication of waters and consequently in the pollution them water bodies. Aiming at the reduction and eventual elimination of the use of phosphate in the detergents, the National Advice of the Environment created resolution CONAMA 359/05, that he makes use on the regulation of the text of match in
\end{abstract}


powder detergents for the use in the national market. The present work has as objective to determine and to compare the concentration of phosphates in powder detergents, manufactured in three countries (Oman, France and Brazil), in accordance with this resolution. To determine the concentration of the phosphate it was used technique of titration for volumetry.

Keyword: Phosphate. Powder detergents. Eutrophication.

\section{Introdução}

Entre todos os solventes conhecidos, o mais antigo e utilizado é a água. Entretanto, como agente de limpeza é deficiente, pois tende a se aglomerar formando gotas esféricas que impedem a miscibilidade entre a água e o ar. O agente capaz de promover a modificação na tensão superficial da água é denominado de tensoativo e é o principal componente dos detergentes comercialmente conhecidos. (Castro, 2001)

O elemento básico do detergente é um agente de superfície ou tensoativo. Aqueles que contém grupos polares ou hidrofílicos, solúveis em água, numa extremidade da molécula e grupos hidrofóbicos/lipofílicos, insolúveis em gordura, na outra extremidade da molécula. $\mathrm{Na}$ maioria dos casos, a parte hidrofóbica é uma cadeia de hidrocarboneto com 8 a 18 átomos de carbono, linear ou ligeiramente ramificada. Em outros casos é possível que um anel benzênico substitua alguns átomos da cadeia. O grupo hidrofílico funcional pode variar amplamente, podendo ser aniônico, cuja atividade superficial é desempenhada por íons negativos (ânions); catiônico, com atividade superficial desempenhada por íons positivos; não iônicos, com molécula inteira superficialmente ativa e dipolares/anfolíticos, com coma atividade que pode ser positiva ou negativa, de acordo com o índice de acidez (pH) da solução. (Castro, 2001)

Essas moléculas reduzem a tensão superficial dos líquidos, sobretudo da água, e facilita a formação e estabilização de soluções coloidais, de emulsões e de espuma no líquido.

Os fosfatos inorgânicos são um dos ingredientes mais utilizados e abundantes na composição dos detergentes em pó de uso doméstico e industrial. Sua função é neutralizar certos íons de metais presentes na água como cálcio e magnésio, diminuindo a dureza da água passa manter o meio alcalino impedindo que a sujeira volte a se fixar nos tecidos, facilitando a ação dos tensoativos. O fósforo na água apresenta-se principalmente nas formas de ortofosfatos, polifosfatos e fósforo orgânico. (Regulamento CE n. ${ }^{\circ}$ 648/2004-União Europeia)

Com o passar do tempo, a utilização crescente desses produtos de limpeza aliada à aplicação não criteriosa de fertilizantes fosfatados nas lavouras levou ao surgimento de problemas ambientais de poluição de águas. Os fosfatos não atuam como materiais tóxicos no ambiente, mas como nutrientes.

O descarte dos compostos de fósforo nos corpos hídricos está diretamente ligado ao uso de detergentes em pó, cuja fonte é o tripolifosfato de sódio - STPP, $\mathrm{Na}_{5} \mathrm{P}_{3} \mathrm{O}_{10}$ (figura 1). 


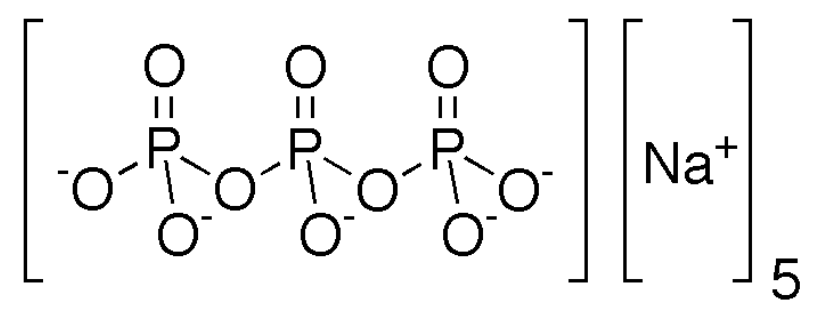

Figura 1 - Tripolifisfato de Sódio (STPP)

Segundo (Osório, 2001), em águas naturais estagnadas, o resultado é o crescimento excessivo de algas, o que pode provocar a eutrofização de mananciais (figura 2).

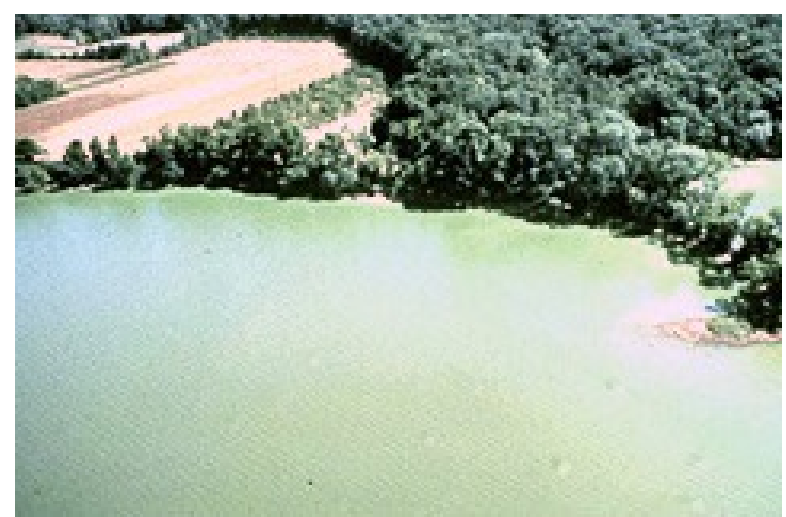

Figura 2 - Eutrofização de um manancial

Sob a pressão dos ambientalistas, surgiram legislações que restringem a adição de fosfatos em detergentes em diversas regiões do mundo. Em grande parte da Europa Ocidental e em regiões industrializadas como América do Norte, Japão e Coreia do Sul já é possível consumir detergentes que não contêm fósforo na forma de tripolifosfato de sódio (STPP). $\mathrm{Na}$ China, muitas regiões têm banido o uso de fosfatos. Porém, permanecem como principal agente estruturante em detergentes de alta performance e ainda são encontrados nas Américas do Sul e Central, África, Leste Europeu e Ásia. (Silva e colaboradores, 2010).

No Brasil, visando à redução e eventual eliminação do aporte de fósforo nos corpos de água, criou-se a resolução CONAMA 359/05, que dispões sobre a regulamentação do teor de fósforo em detergentes em pó para o uso no mercado nacional, conforme mostrado na tabela1. (Silva e colaboradores, 2010)

Torna-se imprescindível determinar a concentração dos compostos de fósforo em amostras de detergentes em pó, cuja fonte é o tripolifosfato de sódio (STPP), visto que estes produtos fazem parte do esgoto doméstico e seu descarte nos corpos hídricos está diretamente ligado ao uso de detergente em pó. (Silva e colaboradores, 2010). 
Tabela 1 - Regulamentação do teor de fósforo em detergentes em pó para o uso no mercado nacional

\begin{tabular}{ccc}
\hline $\begin{array}{c}\text { Prazo de adequação a } \\
\text { partir da publicação desta } \\
\text { Resolução* (03/05/2005) }\end{array}$ & $\begin{array}{c}\text { Limite máximo de } \\
\mathbf{P} \text { por formulação (\%) }\end{array}$ & $\begin{array}{c}\text { Limite máximo de } \mathbf{P}_{2} \mathrm{O}_{5} \text { por } \\
\text { formulação (\%) }\end{array}$ \\
\hline 06 meses (até 03/11/2005) & 5,55 & 12,71 \\
18 meses (até 03/11/2006) & 5,3 & 12,14 \\
36 meses (até 03/05/2008) & 4,8 & 10,99 \\
\hline
\end{tabular}

*Fonte: Resolução CONAMA 359/05

A simples redução do Tripolifosfato de Sódio nas formulações de detergentes sem medidas complementares geralmente acarretam:

. Redução do poder detergente (detergência primária);

. Endurecimento, ao tato, do tecido lavado (incrustações);

. Agrisalhamento do tecido lavado;

. Formação de incrustações nos equipamentos de lavagem. (Luz, A.B., 1995)

Os substitutos mais convenientes e promissores para os fosfatos em formulações de detergentes em pó são as zeólita e aluminossilicatos cristalinos que substituem os cátions causadores da dureza por cátions de sódio. (Osório e Oliveira, 2001)

$$
\mathrm{Ca}_{2}+(\mathrm{aq})+2 \text { Na-zeólita(s) ----- } 2 \mathrm{Na}+(\mathrm{aq})+\text { Ca-zeólita(s) }
$$

A composição química da zeólita na forma sódica pode ser representada pela fórmula genérica. (Osório e Oliveira, 2005)

$$
\mathrm{Na}_{\mathrm{x}}\left\{(\mathrm{AlO} 2)_{\mathrm{x}}(\mathrm{SiO} 2)_{\mathrm{y}}\right\} \mathrm{z} \mathrm{H} 2 \mathrm{O}
$$

Segundo Osório e Oliveira, o uso das zeólitas é amplamente difundido nos Estados Unidos, sendo que no Japão, já em 1984, as zeólitas constituíam o único aditivo em mais de $90 \%$ dos detergentes consumidos e na União Europeia, $75 \%$ dos detergentes contém zeólita e $25 \%$ fosfato.

O presente trabalho tem como objetivo determinar e comparar a concentração de fosfato em detergentes em pó, fabricados em três países (Omã, França e Brasil), de acordo com a resolução CONAMA 359/05.

Diferentes procedimentos de preparo têm sido realizados em amostras para determinação 
de fósforo, os quais envolvem autoclave, forno de micro-ondas doméstico e comercial, mufla, biodigestor e termorreator. Entretanto, verifica-se na literatura que a maior parte dos procedimentos para determinação de fósforo são aplicados às águas, sendo que poucos são os trabalhos que analisam detergentes em pó, visto que se trata de uma matriz complexa que contém mais de 25 ingredientes diferentes. Basicamente, os componentes podem ser classificados em quatro grandes grupos: surfactantes, estruturantes, agentes de branqueamento e agentes auxiliares. O STPP faz parte do grupo dos estruturantes. (Silva e Colaboradores, 2010).

\section{Metodologia}

Todas as análises foram realizadas com reagentes de grau analítico e água destilada. Foram realizados 3 (três) ensaios para cada amostra com diferentes concentrações $(\%, \mathrm{~m} / \mathrm{m})$.

Todas as massas necessárias para o preparo das formulações foram pesadas em balança analítica.

O método proposto visou quantificar o fósforo com base na determinação feita pela precipitação do íon fosfato em fosfomolibdato de amônio. Esse precipitado foi dissolvido em solução alcalina de concentração conhecida, cujo excesso foi titulado.

$\mathrm{O}$ experimento requereu um período de 3 a 4 horas. As soluções foram preparadas antes do inicio do procedimento.

\subsection{Preparo das soluções}

Para o preparo da solução de acetato de magnésio $\left[\mathrm{Mg}\left(\mathrm{C}_{4} \mathrm{H}_{6} \mathrm{O}_{4}\right) \cdot 4 \mathrm{H}_{2} \mathrm{O}\right]$, foi utilizado $2,0070 \mathrm{~g}$ de acetato, adicionando-se $25 \mathrm{~mL}$ de água e no restante,, colocar a vírgula até completar $500 \mathrm{~mL}$, foi adicionado álcool.

Em um balão volumétrico de $250 \mathrm{~mL}$ foi preparadodo a solução de Ácido Clorídrico ( $\mathrm{HCl})(1+2)$, adicionando-se uma alíquota de $83,3 \mathrm{~mL}$ de ácido e completando o seu volume com água destilada.

Para o preparo da solução de Hidróxido de Amônio $\left(\mathrm{NH}_{4} \mathrm{OH}\right)$, utilizou-se um balão volumétrico de $250 \mathrm{~mL}$ adicionando uma alíquota de $125 \mathrm{~mL}$ de hidróxido e completando o seu volume com água destilada.

No preparo da solução do Ácido Nítrico $\left(\mathrm{HNO}_{3}\right)$, foi adicionado a um balão volumétrico de $250 \mathrm{~mL}$ uma alíquota de $125 \mathrm{~mL}$ de ácido e completou-se o seu volume com água destilada.

No preparo da solução indicadora de Fenolftaleína $\left[\mathrm{C}_{6} \mathrm{H}_{4} \mathrm{COO} \cdot \mathrm{C}\left(\mathrm{C}_{6} \mathrm{H}_{4} \mathrm{OH}\right)_{2}\right]$ foi dissolvido $1,0008 \mathrm{~g}$ do indicador em $60 \mathrm{~mL}$ de álcool. Essa solução foi diluída com água até completar o volume de $100 \mathrm{~mL}$. Usou-se de 1 a 2 gotas para cada $100 \mathrm{ml}$ de solução titulada.

Em um balão volumétrico de $50 \mathrm{~mL}$ foi preparada a solução de Tetraborato de Sódio (Bórax) transferindo 1,9068g de bórax e completando o volume com água destilada.

Para o preparo da solução de Hidróxido de Sódio $(\mathrm{NaOH})$ 0,2M tirar a vírgula foi pesado 
$4,0029 \mathrm{~g}$ de hidróxido a 40\%, transferiu-se para um balão volumétrico de $500 \mathrm{~mL}$ e completou-se o volume com água destilada.

Para o preparo da solução de Ácido Clorídrico $(\mathrm{HCl})$ 0,2M foi pipetado 8,24 $\mathrm{mL}$ de ácido clorídrico a a $37 \%$, transferiu-se para um balão volumétrico de $500 \mathrm{~mL}$ e completou-se o volume com água destilada.

\subsection{Procedimento Experimental}

Pesou-se $5 \mathrm{~g}$ da amostra em cápsula de porcelana de $100 \mathrm{~mL}$. Adicionou-se $10 \mathrm{~mL}$ da solução de acetato de magnésio. Evaporou-se até a secagem em banho-maria. Carbonizouse em bico de Bünsen. Incinerou-se em mufla a $550^{\circ} \mathrm{C}$. Esfriou-se. Dissolveu-se as cinzas com ácido clorídrico (1+2). Transferiu-se para um béquer de $400 \mathrm{~mL}$, com auxílio de $80 \mathrm{ml}$ de água. Alcalinizou-se com hidróxido de amônio (1+1). Adicionou-se $10 \mathrm{~g}$ de nitrato de amônio. Acidulou-se com ácido nítrico (1+1). Adicionou-se solução de molibdato de amônio (NH4)6 $\mathrm{Mo}_{7} \mathrm{O}_{2} 44 \mathrm{H}_{2} \mathrm{O}$ ) até completa precipitação. Aqueceu-se por uma hora em banho de água a $(40-45)^{\circ} \mathrm{C}$, agitando frequentemente com bastão de vidro. Esfriou, filtrou e lavou-se o béquer, o bastão de vidro e o filtro com água até que o filtrado não tivesse reação ácida. Transferiu-se o papel-filtro com o precipitado para o mesmo béquer em que foi feita a precipitação. Dissolveu-se o precipitado em solução de hidróxido de sódio $0,2 \mathrm{M}$, medindo em uma bureta. Adicionou-se duas gotas do indicador fenolftaleína. Titulou-se o excesso de hidróxido de sódio com ácido clorídrico 0,2M. (Lutz, 2001).

\subsubsection{Padronização do $\mathrm{HCl}$}

Para padronizar a solução de $\mathrm{HCl}$ utilizou-se como solução padrão de Bórax. Calculouse a molaridade da solução Bórax, encontrando-se o valor de 0,2M. Após o devido cálculo prosseguiu-se com a titulação do bórax contra $\mathrm{HCl}$ 0,2M (teoricamente) obtendose as seguintes medidas de volume gastos de $\mathrm{HCl}: 24,3 \mathrm{~mL} ; 24,2 \mathrm{~mL}$ e $24,4 \mathrm{~mL}$, que implicaram numa média de $24,3 \mathrm{~mL}$ de solução titulante utilizada. A partir desta média realizaram-se os cálculos da titulação na qual determinou-se a concentração de $\mathrm{HCl}$ sendo de $0,2057 \mathrm{M}$.

\subsubsection{Padronização do $\mathrm{NaOH}$}

Para padronizar a solução de $\mathrm{NaOH}$ utilizou-se como solução padronizada anteriormente de $\mathrm{HCl}$ 0,2057M. Prosseguiu-se com a titulação do $\mathrm{NaOH}$ contra $\mathrm{HCl}$ 0,2057M obtendose as seguintes medidas de volume gastos de $\mathrm{HCl}: 24 \mathrm{~mL} ; 23,9 \mathrm{~mL}$ e $24,1 \mathrm{~mL}$, que implicam média de $24 \mathrm{~mL}$ de solução titulante utilizada. A partir desta média realizaramse os cálculos da titulação na qual determinou-se a concentração de $\mathrm{NaOH}$ sendo de 0,1974M.

Neste trabalho utilizou-se a técnica de titulação por volumetria para determinar a concentração de fosfato nas amostras detergente em pó mencionados acima. 


\section{Resultados}

O fosfato, como foi dito anteriormente, é um agente utilizado para neutralizar certos íons de metais presente na água como cálcio e magnésio, diminuindo a dureza da água mantendo o meio alcalino a impedir que a sujeira volte a se fixar nos tecidos e facilite a ação dos tensoativos.

O procedimento foi realizado igualmente por três vezes para cada amostra e apresentado na tabela 2. O resultado final é a média calculada desses três valores, apresentado na tabela 3 .

Os detergentes em pó foram adquiridos nos mercados do Brasil: (Omo Multiação Active Clean) e foi denominado como "Brasil"; de Omã: (Bahar) e foi denominado "Omã" e da França (Omo) e foi denominado "França".

Para determinar o teor de fosfato, em anidrido fosfórico por cento $\mathrm{m} / \mathrm{m}$ existente em cada amostra foi necessário saber a quantidade em $\mathrm{ml}$ de hidróxido de sódio e ácido clorídrico utilizado na titulação. Os dados foram substituídos na fórmula abaixo e os resultados foram apresentados na tabela 2:

$$
\frac{V \times 0,473}{P}=\text { Fosfatos em anidrido fosfórico por cento } \mathrm{m} / \mathrm{m}
$$

Onde:

$\mathrm{V}=$ diferença entre $\mathrm{o} \mathrm{n}^{\mathrm{o}}$ de $\mathrm{mL}$ de solução de hidróxido de sódio $0,2 \mathrm{M}$ adicionado e o $\mathrm{n}^{\mathrm{o}}$ de $\mathrm{mL}$ de ácido clorídrico 0,2M gasto na titulação;

$\mathrm{P}=\mathrm{n}^{\mathrm{o}}$ de $\mathrm{g}$ da amostra.

Os resultados obtidos são expressos em anidrido fosfórico $\left(\mathrm{P}_{2} \mathrm{O}_{5}\right)$. Para saber o teor de fósforo $(\mathrm{P})$ existente na mesma amostra deve-se promover as conversões estequiométricas às formas desejadas. Para se converter os resultados de $\mathrm{P}_{2} \mathrm{O}_{5}$ para $\mathrm{P}$, deve-se multiplicálo por $(2 \times 31) /(2 \times 31)+(16 \times 5)$, ou seja 0,4366 . Para se fazer o inverso, deve-se multiplicar o resultado por $0,4366^{-1}$, ou seja, 2,2904 . 
Determinação da Concentração de Fosfato em Amostras de Detergentes em Pó Utilizando Detecção Titulométrica

Ana Carla da S. Souza - Carlos Eduardo Cardoso - Miguel Rascado Fraguas Neto

Tabela 2: Resultados preliminares

\begin{tabular}{|c|c|c|c|c|c|}
\hline Amostra & $\begin{array}{c}\text { Peso da } \\
\text { amostra (g) }\end{array}$ & $\mathrm{NaOH}(\mathrm{ml})$ & $\mathrm{HCl}(\mathrm{ml})$ & $\begin{array}{l}\text { Teor de Fosfato } \\
\left(\mathrm{P}_{2} \mathrm{O}_{5}\right) \%\end{array}$ & $\begin{array}{l}\text { Teor de Fósforo } \\
\text { (P) \% }\end{array}$ \\
\hline Brasil 1 & 5,0116 & 125 & 120 & 0,4719 & 0,2060 \\
\hline Brasil 2 & 5,0115 & 122,5 & 115,5 & 0,6607 & 0,2885 \\
\hline Brasil 3 & 5,0117 & 127 & 124 & 0,2831 & 0,1236 \\
\hline Omã 1 & 4,9998 & 54,6 & 50 & 0,4352 & 0,1900 \\
\hline Omã 2 & 5,0000 & 50 & 47 & 0,2838 & 0,1239 \\
\hline Omã 3 & 5,0002 & 45 & 43,6 & 0,1324 & 0,0578 \\
\hline França 1 & 5,0011 & 26 & 25,5 & 0,0473 & 0,0206 \\
\hline França 2 & 5,0009 & 27,5 & 25 & 0,2364 & 0,1032 \\
\hline França 3 & 5,0010 & 25 & 23,5 & 0,1419 & 0,0619 \\
\hline
\end{tabular}

Tabela 3: Teores de Fosfato pelo método de titulação

\begin{tabular}{ccc}
\hline Amostra & Teor de Fosfato $\left(\mathbf{P}_{2} \mathbf{O}_{5}\right)(\%)$ & Teor de Fósforo $(\mathbf{P}) \%$ \\
\hline Brasil & 0,4719 & 0,2060 \\
Omã & 0,2838 & 0,1046 \\
França & 0,1419 & 0,0619 \\
\hline
\end{tabular}

Sabendo-se que as amostras "Brasil" e "França" são da mesma marca/fabricante, acreditase que a diferença do teor de fosfato encontrada deve-se ao fato da amostra "França" possuir Zeólitas em sua formulação, já a amostra "Brasil" não possui. 


\section{Considerações Finais}

Ao comparar o teor de fosfato das diferentes amostras analisadas, concluimos que apresentam teores bem abaixo dos parâmetros estabelecidos na resolução CONAMA $359 / 05$

Alguns detergentes utilizam as zeólitas para esta função, mas ainda não se sabe qual o efeito destas espécies no ambiente.

A redução do teor de fosfato nos detergentes, previsto pela resolução, pode ser o começo para sua eliminação, visto que a maioria dos fabricantes já se adequou a essa redução sem maiores prejuízos. 


\section{Referências}

Anônimo. Relatório da Comissão ao Conselho e ao Parlamento Europeu nos termos do artigo $16{ }^{\circ}$ do Regulamento (CE) $n .^{\circ}$ 648/2004 do Parlamento Europeu e do Conselho, de 31 de Março de 2004, relativo aos detergentes, no que se refere à utilização de fosfatos. Disponível em: http://eur-lex.europa.eu/LexUriserv.do?uri=CELEX:52007D C0234:PT:NOT $<$ Acesso em outubro de 2010.

. Fabricantes Iniciam a Redução do Teor de Fósforo em Detergentes em Pó. Abipla em Notícias, Edição nº1. Outubro 2005.

. Determinação do Teor de Fosfato Inorgânico Dissolvido. Universidade de São Paulo - Instituto de Biociências, Laboratório de Limnologia.

Castro, H. F. Processos Químicos Industriais II: Apostila 6. Faculdade de Engenharia Química de Lorena. $1^{\circ}$ Semestre 2001.

Conama (Conselho Nacional do Meio Ambiente). Resolução No 359, de 29 de Abril de 2005. Brasil, 2005.

HENDERSON- Sellers, B. and Markland, H. Z.. "Decaying Lakes: The Origens and Control of Cultural Eutrofication". New York: Wiley. 1987.

Instituto Adolfo Lutz. "Normas Analíticas do Instituto Adolfo Lutz." V.1: Métodos químicos e físicos para análise de alimentos, 3ed. - IMESP - São Paulo, 1985.

Luz, A. B. “Zeólitas: propriedades e usos industriais”. CETEM/CNPq., Rio de Janeiro, 1995.

Paranhos, R. “Alguns métodos para análise da água”. Cadernos didáticos UFRJ. Rio de Janeiro, 1996.

Osório, V. K. L.; Oliveira, W. "Polifosfatos em Detergentes em Pó Comerciais." Química Nova Vol.24 n5. São Paulo - Setembro/ Outubro 2001.

Saldanha, M. E. P. Meio Ambiente: em sintonia com a vida, disponível em: <http://www. abipla.org.br/anuario/pt/meio_ambiente1.html>. Acesso em outubro de 2010. 